SAND78.49

MASTER

Unlimited Helease

\title{
Thermodesorption of Gases From Various Vacuum Materials
}

Leonard C. Beavis

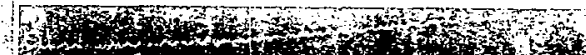
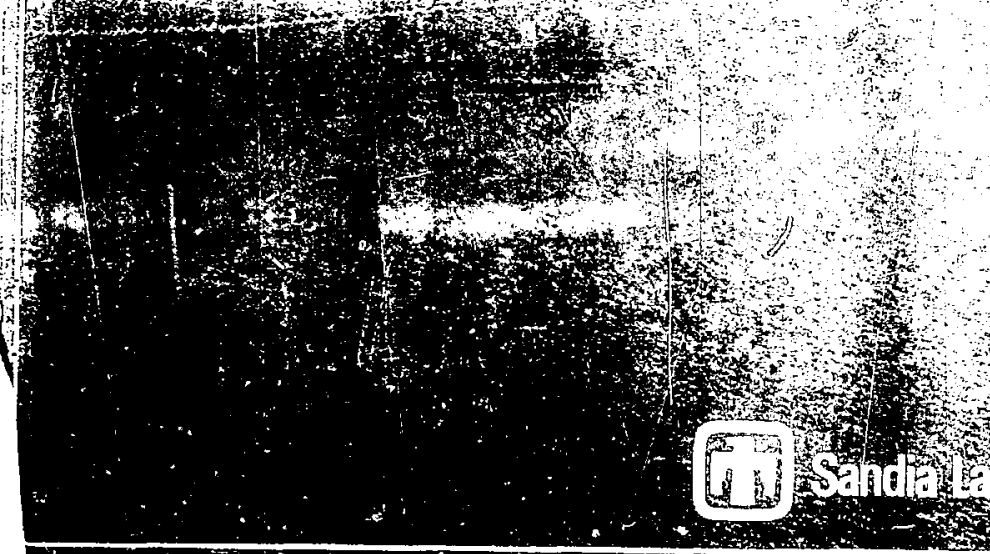


\title{
SAND78 $=1979$ \\ Unl imited Release
}

\section{THERMODESORPTION OF GASES FROM VARIOUS \\ VACUUM MATERIALS}

Printed June 1979

\author{
Leonard C. Beavis \\ Tube Development Division 2354 \\ Sandia Laboratories, A7buquerque, New Mexico 87185
}

\section{ABSTRACT}

A number of materials are commonly used as vacuum system walls. The descr?tion of gases from these materials may contribute significantly to the internal pressure of an unpumped device or to the gas load which a pump must handle in a dynamic system. This report describes the thermodesorption measurements made on a number of metals (molybdenum, nickel, Kovar alloy, copper, copper$2 \%$ beryllium alloy) and two insulators (molybdenum sealing glass ceramic and high alumina ceramic). All of tie materials after typical cleaning and air exposure contain considerable gas. With a long $400^{\circ}-500^{\circ} \mathrm{C}$ vacuum bake, however, all car be cleaned sufficientiy so that they will not contribute appreciable gas to cheir surrounding when vacuum stored at room temperature for many years. Most materials display desorption kinetics which are first order (a single bond or trap energy must be overcome for desorption). It appears that the desorption of $\mathrm{CO}$ from Kovar is rate limited by carbon diffusion ( $D_{0}=.4 \mathrm{~cm}^{2} / \mathrm{s}$ and $\left.E_{d} \simeq 27,000 \mathrm{cal} / \mathrm{mi} 7\right)$. The desorption of hydrogen from glass ceramic also appears to be diffusion rate limited $\left(D_{0} \simeq 1 \times 10^{-3} \mathrm{~cm}^{2} / \mathrm{s}\right.$ and $E_{d} \simeq 11,000 \mathrm{cal} /$ mol). Carbon monoxide is the major gas desorbed from metals, except copper for which hydrogen is the major desorbing species. The insulators desorb hydrogen primarily.

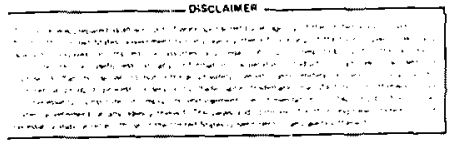


TABLE OF CONTENTS

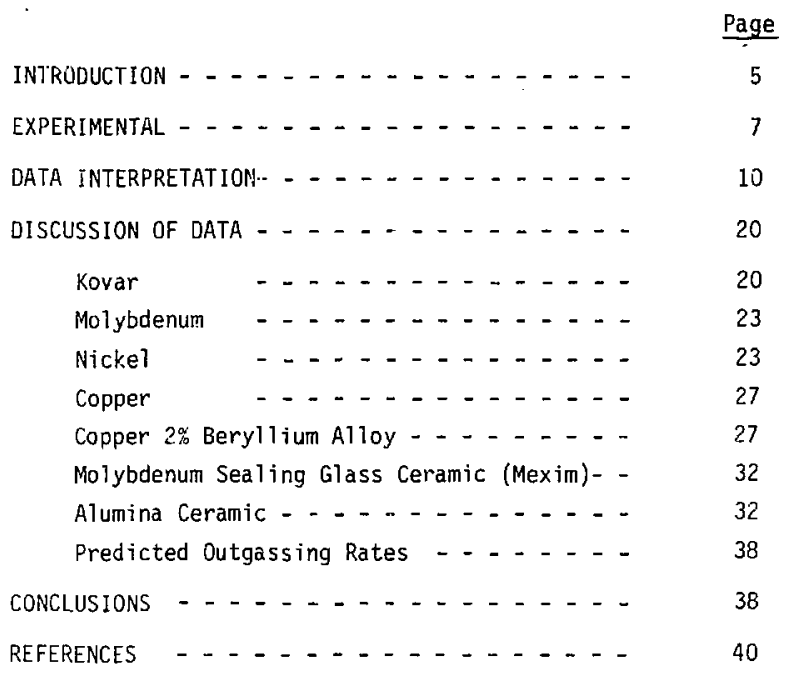


THIS PAGE INTENTIONALLY LEFT BLANK 


\section{INTRODUCTION}

Vacuum workers have long known that all materials they use have at least some gases both in and on them. The purpose of an actively puinping vacuum system is to remove these gases from the experiment or process of interest in the system.

In the case of a static (nonpumped) vacuum envelope, gases from wall materials or materials mounted internally can destroy the vacuum. If we wish to predict the long-term (days or years) gas-up characteristics of a vacuum device, we have the choice of measuring the outgassing rates and permeabilities of materials directly, e.g., under use conditions ${ }^{1}$, or the parameters which go into determining these rates. The rate of gas-up is dependent upon a number of factors. These include mobility of gas in the solids (diffusivity), quantity of gas in (solubility) or adsorbed on the materials, how well the gas is bound to its initial position, the environment (e.g., presence of external gases, temperature) and whether or not sinks for any molecules which reach the gas phase exist.

This report will be confined to outgassing and will not discuss gettering or permeation further, although their importance in long-term predictions cannot be ignored.

Measuring outgassing rates directly is complicated by the dynamic interaction between the samples being measured and the apparatus in which the measurements are made. That is, gases which are being desorbed from the specimen under test react with the walls of the vacuum chamber and may be either sorbed directly or sorbed with displacement of species initially resident. A lower measured rate of desorption is the net effect of such phenomena. ${ }^{2}$ As the specimen outgassing rate decreases, the interaction of the desorbed gases with the measurement system causes increased errors in the estimate of the actual outgassing of the specimen. Because of this and our interest in maintaining low pressures in sma? 1 seaied volumes for periods of years (impiying rates of $10^{-19} \mathrm{~mol} / \mathrm{s}^{2} \mathrm{~cm}^{2}$ or les j), we decided to make measurements of the factors which contribute to outgassing.

Thermodesorption measurements have been made for about the past 20 years, although the technique was first described in 1948 by Apker. ${ }^{3}$ The mathematical description of thermodesorption by first-and second-order kinetics was first given in 1958 by Smith and Aranoff. ${ }^{4}$ Redhead ${ }^{5}$ gives the most complete description 


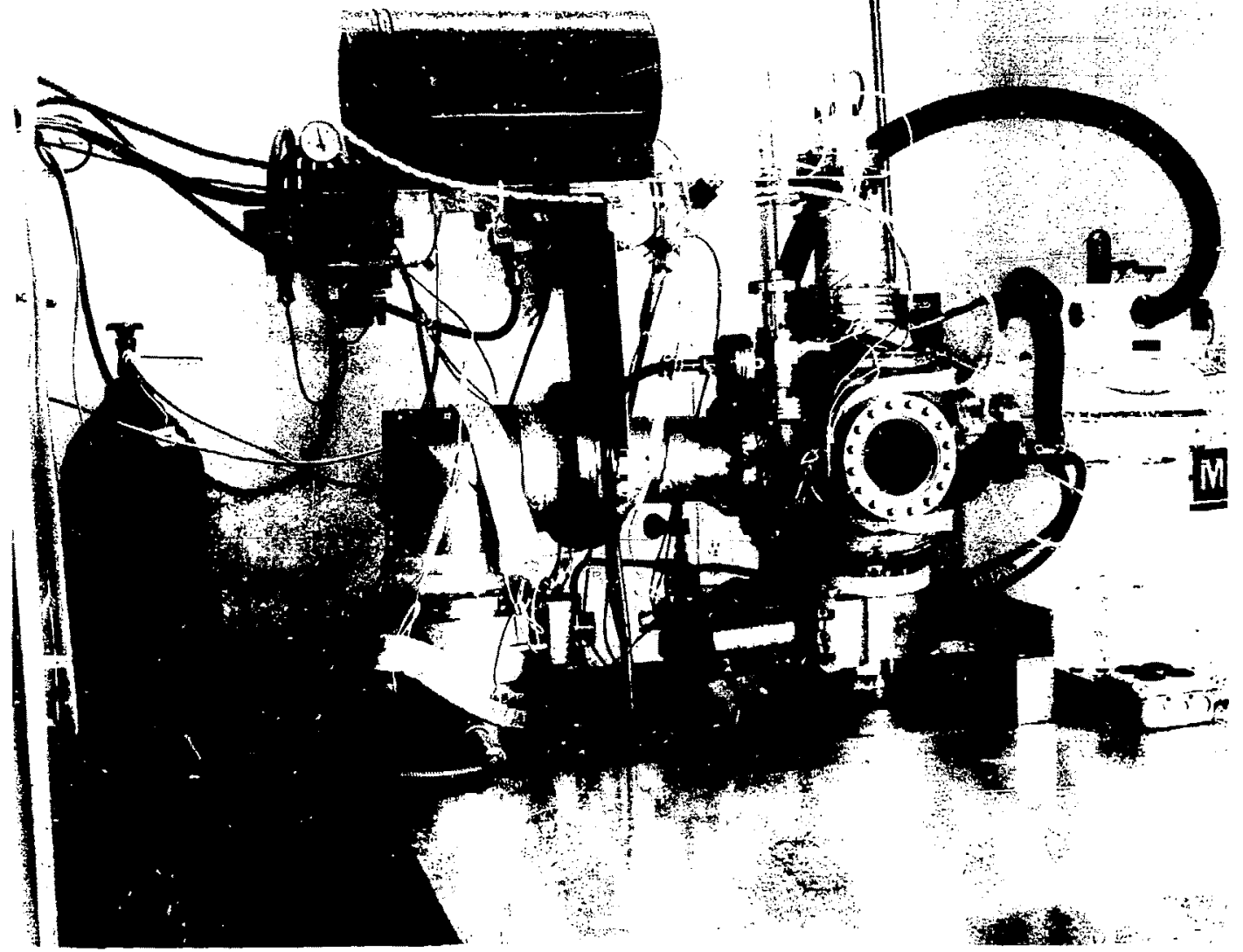

Fig. 1. Photograph of thermodesorption apparatus (Note the QRGA mounted directly over the sample.) 
of simple first- and second-order surface desorption kinetics. Most early works concern themselves with the relationship between the temperature of maximum outgassing rate and the energy required to desorb surface gas (binding energy). Typically, thermodesorption experiments 6,7 were run by heating a filament or ribbon of the material to be studied to very high temperature in order to thoroughty outgas it while the gases were pumped away. The material was then cooled to room temperature. Next, it was exposed to a metered quantity of gas, e.g., 1 Langruir $/ \mathrm{cm}^{2}$ of $\mathrm{CO}$ or $\mathrm{H}_{2}$. The filament was then rapidly heated, either temperature varying linearly with or the reciprocal of temperature time. The pressure profile was measured in either a sealed or rapidly pumped system using a total pressure gauge. The peak or peaks in outgas rate were related to the birding energy by relations given in References 3 or 4 . The materials studied were restricted to refractory conductors, e.q., molybdenum, tungsten, and tantalum.

In the mid-1960s interest developed in the study of nonmetallic materials which exhibited diffusion-controlled desorption of implanted inert gases. 8,9 Finaliy, during the 1970s the importance of peak shape in the analysis of thermodesorption data has been recognized.10,11,12 Also, the influence of multistepped processes on desorption peak shape has been studied.13,14,15

By using all of the information available in thermodesorption peaks, it is sometimes possible to infer the desorption-limiting mechanisms, as well as the activation energies for desorption. As will be pointed out later, it is this information which is required to make outgassing rate calculations for vacuum devices.

The materials for which we have measured thermodesorption spectra include molybdenum, nickel, iron-nickel-cobalt glass sealing alloy hereafter referred to as Kovar, copper, copper $2 \%$ beryllium, molybdenum sealing glass ceramic (referred to as Mexim), and high-alumina ceramic. All these materials are likely to be found in long shelf-life, high-vacuum devices.

\section{EXPERIMENTAL}

The thermodesorption experimental apparatus consists of a bakeable ultrahigh vacuum chamber, associated pumps, a quadrupole gas analyzer which was used because we were interested in the gas species being emitted in addition to the total amount, which was more typical of earlier work, a thermocouple, a programmable high-current source, a Data Trac motor-driven variable resistance to drive 
the current source, a DigitaT Equipment PDP 11/40 computer which was used to collect temperature data, drive the gas analyzer, ard collect gas species quantity information, and the heater which in some instances is the sample. Figure 1 is a photograph of the apparatus.

There are several precautions which were taken to minimize errors in and simplify data interpretation. Ideally, one wishes to measure only the gases being desorbed by the specimen. In most instances, the desorbed gases interact with the vacuum system in some ill-defined fashion which includes substitution of one species for another on the interior of the vacuum system. The impact of these processes is minimized by using a mercury diffusion pump diring measurements. The ion pump on the system was found ta regurgitate gases when subjected to even small louds of active gases. This pump is used to maintain the system in a relatively clean condition during periods when measurements are not being made. A small volume-to-chamber pumping speed (exit conductance) ratio ( $/ C$ ) al $\leqq 0$ helps reduce extraneous interaction in addition to improving the time/termperature vs outgas rate resolution. Our system has a $V / C$ of $\approx 0.1 \mathrm{~s}$ for mass $=28 \mathrm{AMU}$. The gas analyzer is located directly over the sample so that most gases measured have not collided with a cold wall.

The temperature ramp is made linear by empirically adjusting the motordriven resistor (Research Inc. Data Trac) which controls trie programable current source. Ramp rates of $1 \mathrm{~K} / \mathrm{s}-100 \mathrm{~K} / \mathrm{s}$ were achieved; most measurements were made with a $5 \mathrm{k} / \mathrm{s}-10 \mathrm{k} / \mathrm{s}$ ramp.

Two types of samples have been measured. The first class included those wuich could be fabricated into thin conducting foils less than $0.1 \mathrm{~mm}$ thick, i.e., molybdenum, nickei, and Kovar. These samples were heated by passing a current directiy through them. The measurement thermocouple was attached to the center of the foil. Foils were Kovar, $0.075 \mathrm{~mm} \times 6.4 \mathrm{~mm} \times 89 \mathrm{~mm}$; nickel, $0.05 \mathrm{~mm} \times 6.4 \mathrm{~mm} \times$ $50 \mathrm{~mm}$; and molyodenuni, $0.025 \mathrm{~m} \times 6.4 \mathrm{~mm} \times 50 \mathrm{~m}$. They were attached to heavy copper electrodes ( $6.4 \mathrm{~mm}$ diameter). A disadvantage of measuring foils by this method was that a zone near each heavy copper conductor was not at the same temperature as the remaining foil when it was heated. This deviation becomes greater the higher the temperature of the center. At high temperature $\left(>1000^{\circ} \mathrm{C}\right)$, we estimated the non-uniform zone may have accounted for 10-15\% of the sample length. The second class of samples included copper, molybdenum, alumina ceramic, copper $2 \%$ beryllium alloy, and glass ceramic. These were heated in a furnace as 
described by Patrick. 16 The heater was capable of accepting samples of about $10 \mathrm{~mm}$ on a side. Typital samples were discs $10 \mathrm{~mm}$ in diameter by $1 / 2 \mathrm{~mm}$ thick. The temperature was monitored with a thermocouple mounted to the bottom cover of the heater. The sailple was initially mounted for a desorption measurement in a tubular holder away from the heater. After pumpdown, the empty heater was ramped. This preliminary outgassing was followed 30 minutes latir by a second temperature ramp during which mass spectra were obtained. These two runs produced the background spectra. Finally, after an additional 30-minute wait, the sample was dropped into the heater; it was ramped to the maximum temperature for which data were desired. Mass spectra were again obtained. To analyze the data, the background values were subtracted from the sample values in order to obtain sample only mass spectra. For samples which needed to be heated above $1200^{\circ} \mathrm{C}$, the walls of the chamber were cooled with liquid nitrogen in order to reduce outgassing from them. The main limitations of this desorption technique were: samples did not always fall to the bottom of the heater where the thermocouple was located. Temperature gradients in the sample introduced uncertainties in its temperature. We compared the desorption spectra for molybdenum using directly heated folls and a disc sample. They were in close agreement (peaks occurred within $20 \mathrm{~K}$ for the two samples).

Detection and quantification of desorbed gas species were accomplished using a computer-controlied quadrupole mass spectrometer (QRGA UTI Model 100B). The programaed computer put out voltages to the QRGA sweep control circuit which tuned the mass-to-charge ratio (mass number) of the QRGA. Any mass number from 1 to $10 \mathrm{C}$ could be tuned. Typically, mass numbers $2\left(\mathrm{H}_{2}\right), 15\left(\mathrm{CH}_{3}^{+}\right), 16\left(\mathrm{CH}_{4}^{+}, 0^{+}\right), 18\left(\mathrm{H}_{2} \mathrm{O}^{+}\right)$ $28\left(\mathrm{CO}^{+}\right), 32\left(0_{2}^{+}\right), 40(\mathrm{Ar})$, and $44\left(\mathrm{CO}_{2}^{+}\right)$were measured at least once for each sample type. Then the list of peaks scanned was reduced to the 4 or 5 which had the largest signal on the first sample. The electron multiplier current for each peak was fed through a 7-decade ( $1 \mathrm{~V} /$ decade) logarithmic amplifier to an analogto-digital converter and then to the computer. Thermocouple roadings were sent through a similar channel to the computer. Data were stored on a 1-milition-word disk. Because of the slow response of the $\log$ amplifier in the $10^{-11}-10^{-12}$ ampere ranges, the scan rate of the URGA was Iimited to about 10 mass peaks/s. Typical sampling times were $150-200 \mathrm{~ms}$ on most spectra. On the fastest ramps (50 K/s $100 \mathrm{~K} / \mathrm{s}$ ), only one species was monitored per sample in order that shorter sampling 
times could be used. A large dynamic range was not required of the log amplifier under single-mass-peak monitoring. The system was calibrated by the use of a standara leak for each of the gases (except $\mathrm{H}_{2} \mathrm{O}$ ) we expected to see desorbed. Figure 2 shows a block diagram of the system and its interconnection.

\section{DATA INTERPRETATI'N}

There are a number of potential mechanisms which would allow gas to be released into a vacuum envelope. These mechanisms, because of difference in their fundamental nature, can lead to differences in the amount of gas seen in the vacuum as a function of time and temperature. There are three simple mechanisms with which we will be concerned. In addition, combinations of these could also be considered but will not be here. The three simple mechanisms are illustrated in Figure 3. The samples in the figure deal with (or use) co but are applicable to other polyatomic molecules (e.g., $\mathrm{H}_{2}, \mathrm{CO}_{2}$ ). For first-order desorption, imagine that the surface is covered with molecules ( $\mathrm{CO}$ in Figure 3.a). These may be migrating or stationary on the surface. Through random thermal processes, as molecules receive enough energy, they leave the surface and appear in the gas phase. In this case, release to the gas pizse is considered to be first-order rate limited because only the single bond to the surface need be broken in order for the molecule to appear as gas. In the case of second-order kinetics, imagine the surface to be randomly covered with the constituent atoms of a diz:oraic molecule (carbon and oxygen in figure 3.b). If the rate of appearance of molecules in the gas phase is limited by the combination of the different atoms to form the molecules, then the rate is second order. Finally, consider the mechanism of bulk diffusion. In Figure 3.c, the bulk is shown to contain carbon atoms. It is also possible that the surface may contain these atoms. The rate of desorption is limited by the rate at which one or both of the reactants move through the bulk to the surface to be desorbed.

The mathematical descriptions for these desorption mechanisms, first order, second order, or diffusion, are well known. ${ }^{4,10}$ The first- or second-order desorption rate equation is

$$
-i d=v_{i} H^{i} \exp (-E / R T)
$$




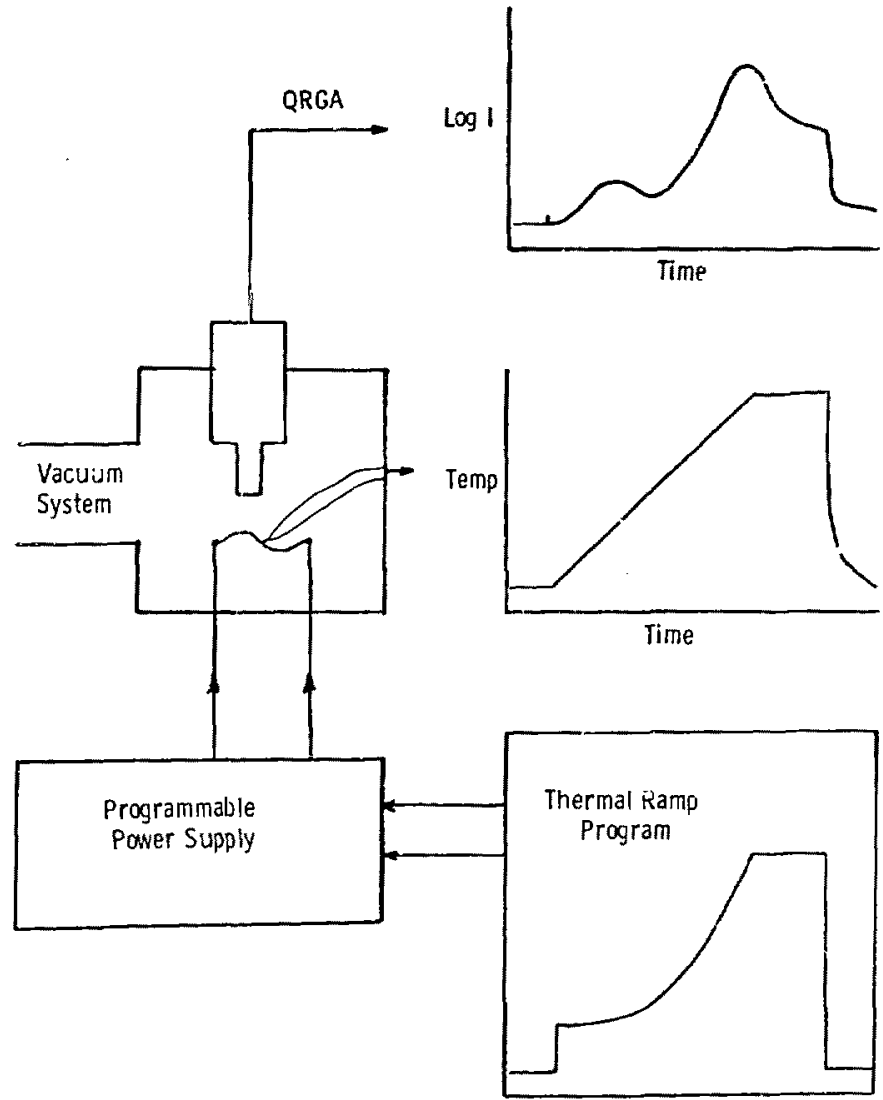

Fig. 2. Block diagram of the thermodesorption apparatus with illustrations of the various input and outpuc signals associated with a measurement 


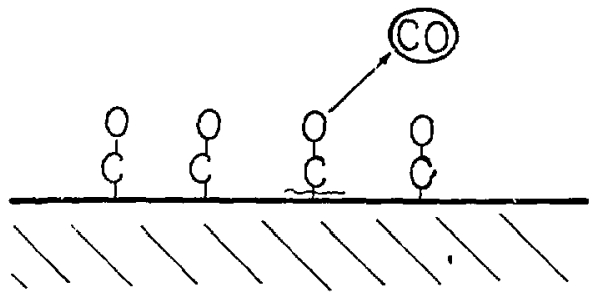

\section{lst Order}

(a)

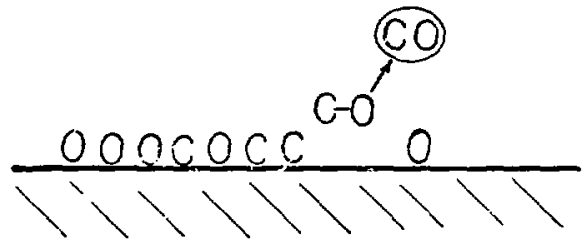

2nd Order

(b)

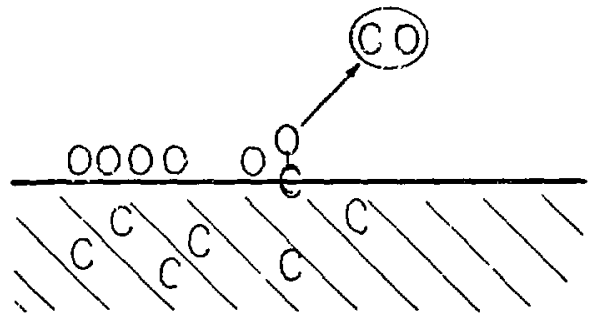

Diffusion

(c)

Fig. 3. Iilustration of first order, second order, and diffusion limited desorption. 
where

$$
\begin{aligned}
& i=\text { order of reaction, } 1 \text { for first order, } 2 \text { for second order; } \\
& v_{i}=\text { irequency term for the reaction; } \\
& N=\text { coverage of the surface }\left(\text { particles } / \mathrm{cm}^{2}\right) ; \\
& E=\text { binding energy of the species }(\mathrm{kcal} / \mathrm{mol}) ; \\
& R=\text { gas constant }\left(1.99 \times 10^{-3} \mathrm{kcal} / \mathrm{mol} \mathrm{K}\right) ; \\
& T=\text { absolute temperature }(\mathrm{K}) .
\end{aligned}
$$

For diffusion-controlled desorption, the rate equation is

$$
\frac{\partial C}{\partial \tau}=\frac{\partial^{2} C}{\partial x^{2}} \quad \text { (Fick's Law) }
$$

In this equation, $\tau$ is a pseudotime defined in Ref. 10.

$$
\tau=\int_{0}^{t} D(t) d t \text { and } D\left(-j=D_{0} \exp \left(-E_{d} / R T\right)\right.
$$

where

$$
\begin{aligned}
E_{d} & =\text { the activation energy for diffusion (kcal/mol); } \\
t & =\text { time (seconds). }
\end{aligned}
$$

In the experiments we performed, the temporal dependence of temperature was

$$
T=T_{0}+\hat{B} t
$$

where

$$
\begin{aligned}
& T_{0}=\text { initia! temperature; } \\
& \beta=\text { heating rate }(\mathrm{K} / \mathrm{s}) .
\end{aligned}
$$

Equations (1) and (2) are derived assuming that gas is removed from the system at a high rate compared to the hoating rate $\left(i . \mathrm{e} ., \frac{V}{\mathrm{C}}<\frac{\mathrm{J}}{\mathrm{Q}}\right)$.

It is worth emphasizing here that our desorption experiments were quite differpnt from those described in the earlier literature. ${ }^{2-y}$ in our measurenents, 
we looked at gases which were desorbed from materials exposed to air after cleaning and low temperature bake $\left(500-700^{\circ} \mathrm{C}\right)$. In the referenced experiments, the first step is a high-temperature flash $(>2000 \mathrm{~K})$, nomally followed by the introduction of the gas to be studied, then another high-tamperature ramp during which the desorption is measured. We measurej various desorbed species by mass spectrometry, whereas the earliter experimenters metusured a total pressure and assumed it was the gas which they tried to introduce in a controlled fashion. Additionally, investigators which doped samples with specific gases usually had some preconceived idea of the rate-jimiting mechanism for desorption. It was normally assumed to be first-order (occasionally second-order) rate limited. These investigators then easily analyzed their thermal desorption peaks. The thermal desorption peak(s) may be easily analyzed by solving equation (1) for the temperature at the peak desorption rate $\left(T_{p}\right) ;^{4}$

$$
\frac{E}{R T_{p}^{2}}=\frac{v}{B}-\exp \left(\frac{-E}{R T_{p}}\right) \text { for first order, }
$$

or

$$
\frac{E}{R T_{p}^{2}}=\frac{\nu_{2} N_{0}}{3} \exp \left(\frac{-E}{R T_{p}}\right) \text { for second order. }
$$

In equation (6), the initial surface coverage $N_{0}$ has been substituted for

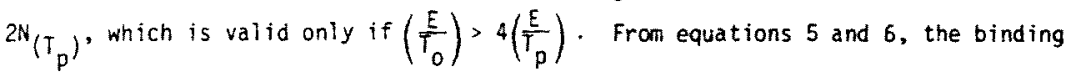
energy of the rate-limiting step may be found. If diffusion is the rate-controlling mechanism, the temperature at which the peak outgas rate oc urs depends not only on the geometry of the sample, the activation energy of diffusion, the initial bulk concentration, and the concentration profile of the species controlling desorption, but also upon $D_{0}$, which unlike $v_{1}$ or $v_{2}$, can vary over many orders of magnitude. Thus, data analysis of diffusion-controlled desorption is much more complex.

If the mechanism of the rate-limiting step is known with certainty, even if it is diffusion controlled and $D_{0}$ must be estimated, then the energetics for the 
mechanism can be found. In our desorption measurement, we are not certain what the rate-limiting mechanism was and this complicated data analysis. From the outgassing versus temperature data (peak shape) in Figure 4, it was possible to determine. whether diffusive first- or second-order kinetics control desorption (for example, see refs. 6 and 10). Typically, first-arder desorption exhibits a narrow asymmetric peak. The second-order peak'will be somewhat broader with diffusion-controlled kinetics having the broadest peak for any but extremely thin samples. The rate-controlling mechanism can be found in a number of ways. All of these methods depend upon knowing peak shape in addition to the temperature where the peak uutgassing rate occurs.

We have used two methods primarily in obtaining and analyzing desorption data (see Figure 5). The first method compared the upper half of actual thermal desorption peak with those shapes predicted by the various rate limiting mechanisms. The upper portion of Figure 5 illustrates the regions where data were compared to the single theoretical models. Ii instead of carrying the temperature ramp through the entire thermal desorption peak, the ramp was stopped ( $T$ = constant with time), see Figure $5 . b$, at some point on the rising edge of the desorption peak, then the outgassing decays with characteristics which were dependent upon the rate limiting step. This was the second method of obtaining information on the rate limiting mechanism. Using either of the general methods it was possible to discern the rate controlling mechanism because the peak shape of the desorption as a furction of temperature (method 1) or time (method 2) is unique to the kinetics. A more complete description of these methods is given below.

The thermal desorption peak shape for first- and second-order rate-limiting mechanisms may be defined in terms of the ratio $\dot{N}_{j} / \dot{N}_{p}$ of the rate outgassing at any temperature $T_{j}$ to the maximum rate observed at $T_{p}$. Equation (1) gives both rates. Their ratio is

$$
\frac{\dot{N}_{j}}{\dot{N}_{p}}=\left(\frac{N_{j}}{N_{p}}\right)^{i} \exp \left[\frac{E}{R}\left(\frac{1}{T_{p}}-\frac{1}{T_{j}}\right)\right] \text {. }
$$




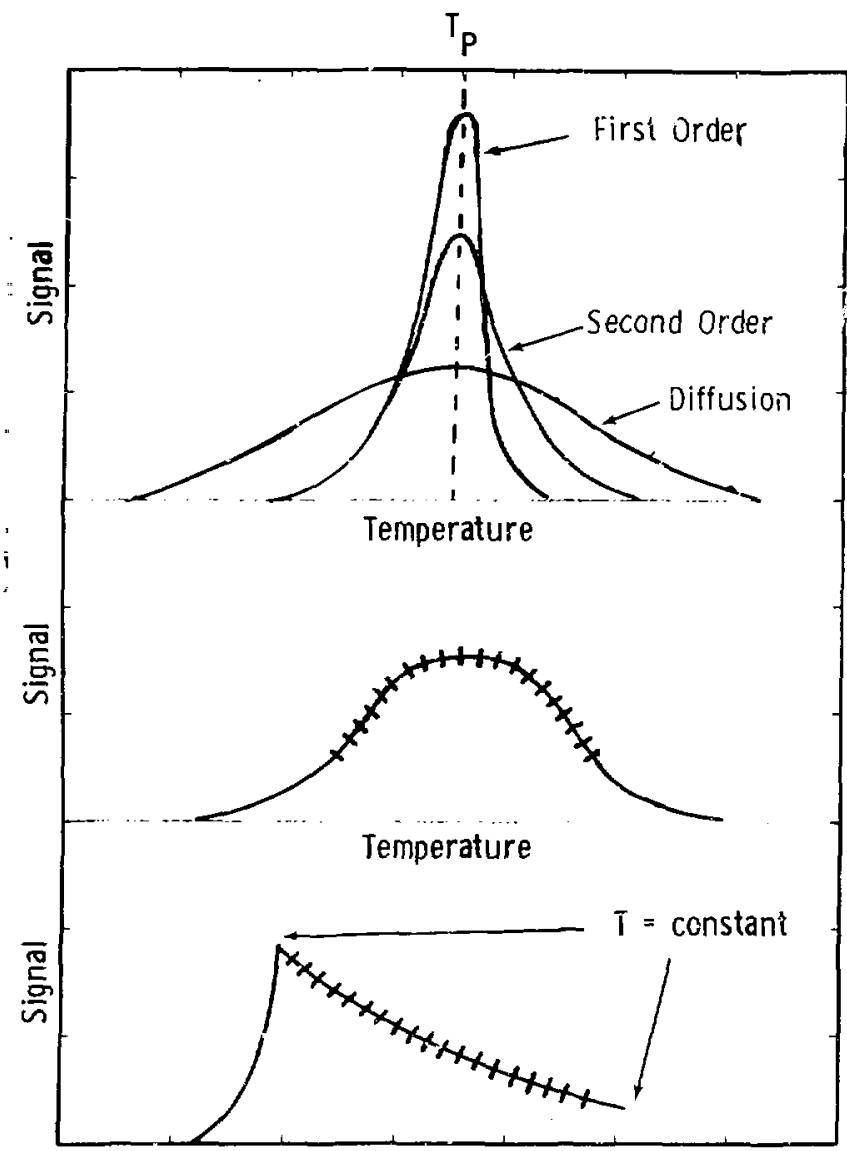

Time
Fig. 4. Typical peak shapes for desorption controlled by ist crder, 2nd order, and diffusion inechanisms.

Fig. 5. Illustration of the portion of data analyzed to determine the rate controlling mechan i sm. (a)

(b) 
Determination of the ratio $N_{j} ; N_{p}$ rrquires integration of equation (1). A new function is defined; $i=1$ or 2 for first-order or second-order kinetics, respectively.

$$
F_{k, j}=\frac{{ }^{v} i}{3} \int_{T_{k}}^{T_{j}} \exp \left(\frac{-F}{\overline{R T}}\right) d T .
$$

Then, for First-order desorption

$$
\frac{\dot{N}_{j}}{\dot{N}_{p}}=\exp \left[\frac{E}{R}\left(\frac{1}{T_{p}}-\frac{1}{T_{j}}\right)+f_{j, p}\right] \text {, }
$$

and for second-order desorption

$$
\frac{\dot{H}_{j}}{\dot{V}_{p}}=\exp \left[\frac{E}{R}\left(\frac{1}{T_{p}}-\frac{1}{T_{j}}\right)\right] /\left(1+i_{p} f_{p, j}\right)^{2},
$$

where " $\mathrm{p}$, the coverage at the desorption rate maxinum, is related to the initial coverage $N_{0}$ by

$$
\left(\frac{1}{N_{p}}\right)=\left(\frac{1}{N_{0}}\right)+f_{0, p} .
$$

The integrals $f_{k, j}$ are evaluated as follows: (1) For E/RT = 9, convergence is best for the series

$$
f_{k, j}=\frac{\nu_{i} E}{3 R}\left[\frac{\exp \left(\frac{-E}{R T}\right)}{T_{j}}\left(1+\frac{2 !}{\left.\frac{-E}{R T}\right)^{2}}+\frac{3 !}{\left(\frac{-E}{R T}\right)^{2}}+\frac{4 !}{\left(\frac{-E}{R T}\right)^{3}}+\frac{5 !}{\left(\frac{-E}{R T}\right)^{4}}\right)\right] ;
$$


(2) for E/RT \& 9, the iollowing expression is easier to use.

$$
f_{k, j}=\frac{\nu_{j} E}{\partial R}\left[{ }^{T}{ }^{T} \frac{\exp \left(\frac{-E}{R T}\right)}{\frac{E}{R T}}+E_{i}\left(\frac{-E}{R T}\right)\right] \text {, }
$$

where $E_{I}$ is the exponential integral.18

For diffusion-contralled desorption, assume the desorbing membrane to have thickness $2 l$ and to contain $C_{0}$ atums $\mathrm{cm}^{-3}$ of the diffusing species, uniformly distributed through the sample. With these assumptions, Carslaw and Jaeqer 19 give the desorption rate per unit areas as

$$
\begin{aligned}
& \qquad \dot{N}_{j}=\frac{i D\left(T_{j}\right)^{C} 0}{2} \sum_{j=0}^{\infty} \exp \left[-(2 j+1)^{2}{ }^{2}\left(\frac{T_{j}}{4 \ell^{2}}\right)\right], \\
& \text { where } \quad{ }_{\tau_{j}}=\frac{1}{B} \int_{T_{0}}^{T_{j}} D_{0} \exp \left(\frac{-E}{R T}\right) d T \quad \text { from equations (3) and (4). }
\end{aligned}
$$

The pseudotime, ${ }^{\tau} j$, is evaluated similar to $f_{k, j}$ in equations (11) and (12). A simple and cormonily used method of desorbing gas is through isothermal annealing. The sample is rapidly raised to some temperature $T$ where desorption is known to occur and held at that temperature. The time to achieve $T$ must be such that appreciable desorption does not take place before measurements can be made. The desorption rates versus time are given by

$$
\begin{array}{ll}
\dot{N}(t)=-r_{1} N_{0} \exp (-\gamma, t) & \text { first order } \\
\dot{N}(t)=-r_{2} /\left(\gamma_{2} t+\frac{1}{N_{0}}\right)^{2} & \text { second } r \cdot \text { der }
\end{array}
$$




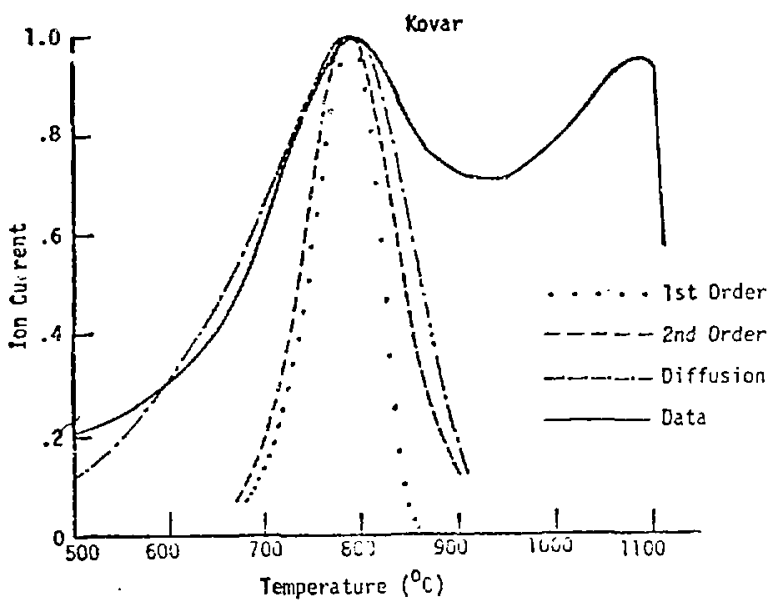

Fig. 6. Comparison of various theoretical desorption spectra with data from a single Kovar desorption of carbon monoxide. 


$$
\dot{N}(t)=\frac{D C_{0}}{(\pi D t)^{1 / 2}}\left[1+2 \sum_{n=1}^{\infty}(-1)^{n} \exp \left(\frac{-n^{2} \ell^{2}}{D t}\right)\right] \quad \text { diffusion }
$$

where

$$
\begin{aligned}
& r_{i}=v_{i} \exp \left(\frac{-E}{R T}\right), \text { and } \\
& c_{0}=\text { initial tulk concentration of diffusing atoms. }
\end{aligned}
$$

It should be noted that equation (16) is used where $2 t / l^{2}<0.3$ because of its rapid convergence. $D t / l^{2}$ will be small for reasonable imes at any temperature $r !$ the rising jide of a desorption peak.

\section{DISCUSSION OF DATA}

Kovar

Kovar primarily desorbs carbon monoxide. Some carbon dioxide is desorbed in the $400-600^{\circ} \mathrm{C}$ range. Because carbun monoxide ions are fragments of carbon dioxide in the QRGA, the low-temperature portion of the CO desorption peak is somewhat overestimated. The amount of water desorbed is typically small; when it does appear, it desorbs at $200^{\circ} \mathrm{C}$ or less. Occasionally, hydrogen and water were noted in the system at sample temperatures aver $1000^{\circ} \mathrm{C}$. This was ascribed to desorption from the vacuum system walls due to the radiant energy from the sample. In comparing chemically cleaned Kovar with that as received from the manufacturer and degreased, an order of magnitude more gas was desarbed from the "as received" material than from the cleaned material. Chemical cleaning consists of a $900^{\circ} \mathrm{C}$ one-hour wet hydrogen firing to remove carbon followed by an $800^{\circ} \mathrm{C}$ one-hour vacuum fire to remove hydrogen. From the cleaned Kovar, it appears that apprcximately one monolayer $\left(9 \times 10^{14} / \mathrm{cm}^{2}\right)$ of carbon monoxide was desorbed at temperatures up to about $1000^{\circ} \mathrm{C}$. Most of this gas comes in one large peak which, depending on the temperature ramp rate, occurs at $700^{\circ} \mathrm{C}$ to $850^{\circ} \mathrm{C}$, Figure 6 . The data indicate that this large peak is much too broad to be caused by either a single first-order or second-order desorption rate-1imiting step, which are $p$ ? otted on Figure 6 along with the diffusion calculation and the actual data. 
Isothermal anneals indicate $t^{-1 / 2}$ tine dependence of the peak decay. Therefore, it appears that this peak could best be explained on the basis of a diffusion rate-limiting mechanism. Carbon monoxide probably does not diffuse as a molecule in Kovar; but it can diffuse as its constituents; i.e., carbon and oxygen. The measurements indicate on the basis of diffusion-limited desorption an activation energy for diffusion of $27.5 \mathrm{kcal} / \mathrm{mol}$ with a $D_{0}$ of approximately $0.4 \mathrm{~cm}^{2} / \mathrm{s}$. The diffusion parameters reported for carbon diffusion in gamma iron are 20 activation energy, 27 to $40 \mathrm{kcal} / \mathrm{mol}^{\text {; }}$ and $\mathrm{D}_{0}, .04$ to $0.6 \mathrm{cmi}^{2} / \mathrm{s}$. Kovar is face-centered cubic (gamma phase at room temperature and above). Notis ${ }^{21}$ studied the decarbonization of a Kovar-like alloy in wet hydrogen. He reported a diffusion activation energy for carbon of $25.6 \mathrm{kcal} / \mathrm{mol}$ with a $0_{0}$ of $.0085 \mathrm{~cm}^{2} / \mathrm{s}$. The data from our experiments were toward the low end of the range of reported values for the energy of diffusion and mid-range for $D_{0}$.

Kovar always shows two desorption peaks; the second one could not be totally measured because of possible melting of the alloy. The outgassing spectra from Kovar can be explained as two diffusion-limited processes (see Figure 7). At low temperatures, the layer on the surface is probably primarily oxygen from air exposure. As the Kovar is heated, eventually the carbon inside the alloy becomes mobile. It comes to the surface, reacts with the oxygen, and then desorbs as co. In this temperature regime, the rate-limiting step is that of carbon diffusion through the bulk of the Kovar. As the temperature is raised, the surface oxygen is finally completely depleted and the amount of $\mathrm{CO}$ desorbing decreases due to oxygen starvation. At this temperature, $\approx 800^{\circ} \mathrm{C}$ on a slow ramp, there is probably still oxygen dissolved in the buik, and there is certainly carbon. The oxygen at this point is not mobile enough to move within the solid. As the temperature continues to increase to $1100^{\circ} \mathrm{C}$, the butk oxygen becomes mobile. It diffuses to the surface where it combines with already-mobile carbon and desorbs. This then makes up the high-temperature co desorption peak observed from kovar. This explanation, although not unique in explaining the observed behavior of Kovar, is the simplest explanation.

Finally, it should be noted wnat it is possible that carbon monoxide may be bound to the Kovar surface with energy greater than the activation energy for diffusion. Although the diffusion process was measured at high temperatures $\left(>700^{\circ} \mathrm{C}\right)$, it is possible that at room temperature or somewhat higher temperatures, 

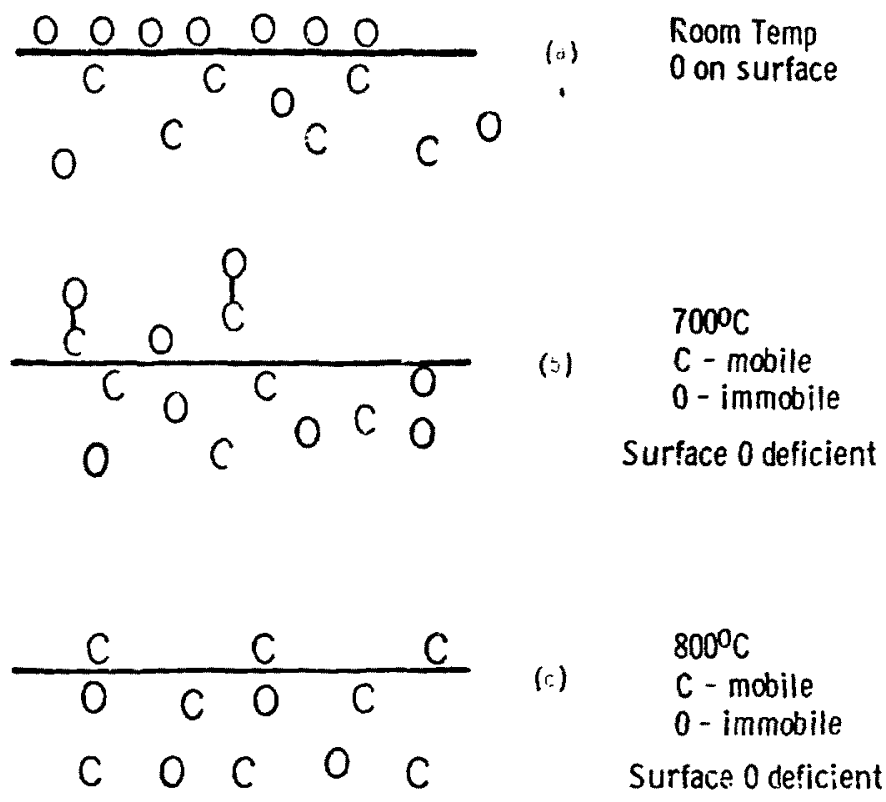

(c) $\quad C$-mobile
0 -immobile
Surface 0 deficient

0

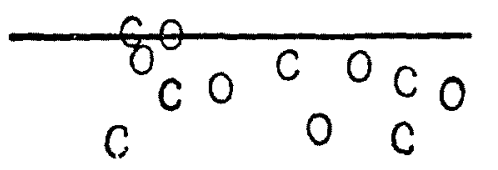

(.1)

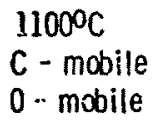

Fig. 7. Illustration of carbon and oxygen diffusion in Kovar and how they wht account for the co desorption spectra observed. 
the rate-limiting step might be due to first-order or second-order desorption. For example, if the first-order binding energy is about $50 \mathrm{kcal} / \mathrm{mol}$, then at room temperature the desorption rate will be controlled by the $50 \mathrm{kcal}$ bonds and not the diffusion process.

Molybdenum

Molybdenum primarily desorbs carbon monoxide. Figure 8 compares first-order and second-order desorption of carbon monoxide with the measured desorption spectra. Typically, the amount of gas desorbed is $8-9 \times 1 \mathrm{C}^{15} / \mathrm{cm}^{2}$. Most of this appears at temperatures over $1000^{\circ} \mathrm{C}$ (see Figure 9). A few percent (1-6\%) appears at somewhat Jower temperatures $\left(2700^{\circ} \mathrm{C}\right)$. This desorption wäs apparently one or more first-order desurption peaks (determined by $e^{-t}$ relationship of isotherma 1 treatment). The energy of desorption for this peak is 61-64 kcal/mol. Most of the $\mathrm{CO}$ desorbs at about $1100^{\circ} \mathrm{C}$. This is a first-order desorption peak whose binding energy is $97 \mathrm{kcal} / \mathrm{mol}$. It was interesting to observe that as molybdenum was thermally ramped several times, the desorption peaks moved to slightly lower temperatures after the first bakeout. Undoubtedly, this phenomenon has something to do with molybdenum recrystallization which becomes quite rapid at teimperatures over $900^{\circ} \mathrm{C}$. The binding energies appear to be reduced about $5 \%$ after the first desorption.

\section{Nickel}

Carbon monoxide is the primary gas desorbed from nickel. Typically, three desorption peaks were seen (see Figure 10). The apparent total coverage was about $4 \times 10^{15} / \mathrm{cm}^{2}$. The lowest temperature peak occurs at about $400^{\circ} \mathrm{C}$ and is firstorder. Its binding energy is $40-42 \mathrm{kcal} / \mathrm{mol}$. The second peak occurs at about $800-1000^{\circ} \mathrm{C}$ and may be several first-order peaks or a diffusive peak. The third peak, which occurs at $1000-1100^{\circ} \mathrm{C}$, is either first or second order. Because the first- and second-order peaks are very nearly the same shape, the mechanism was not determined unequivocally. In either event, the binding energy is about 90 $\mathrm{kcal} / \mathrm{mal}$. 


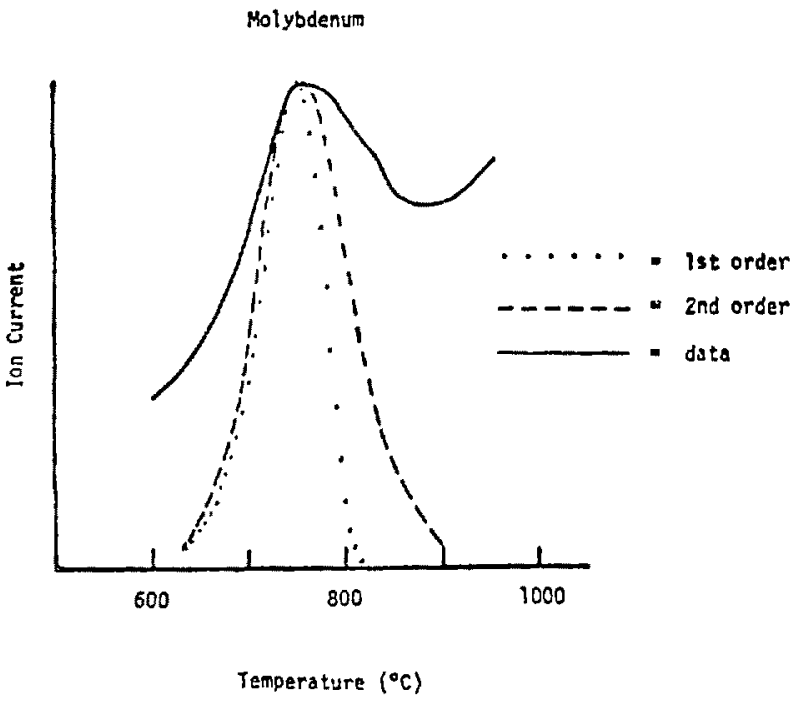

Fig. 8. Comparison of various theoretical desorption spectra with data from a single molybdenum desorption of carbon monoxide. 


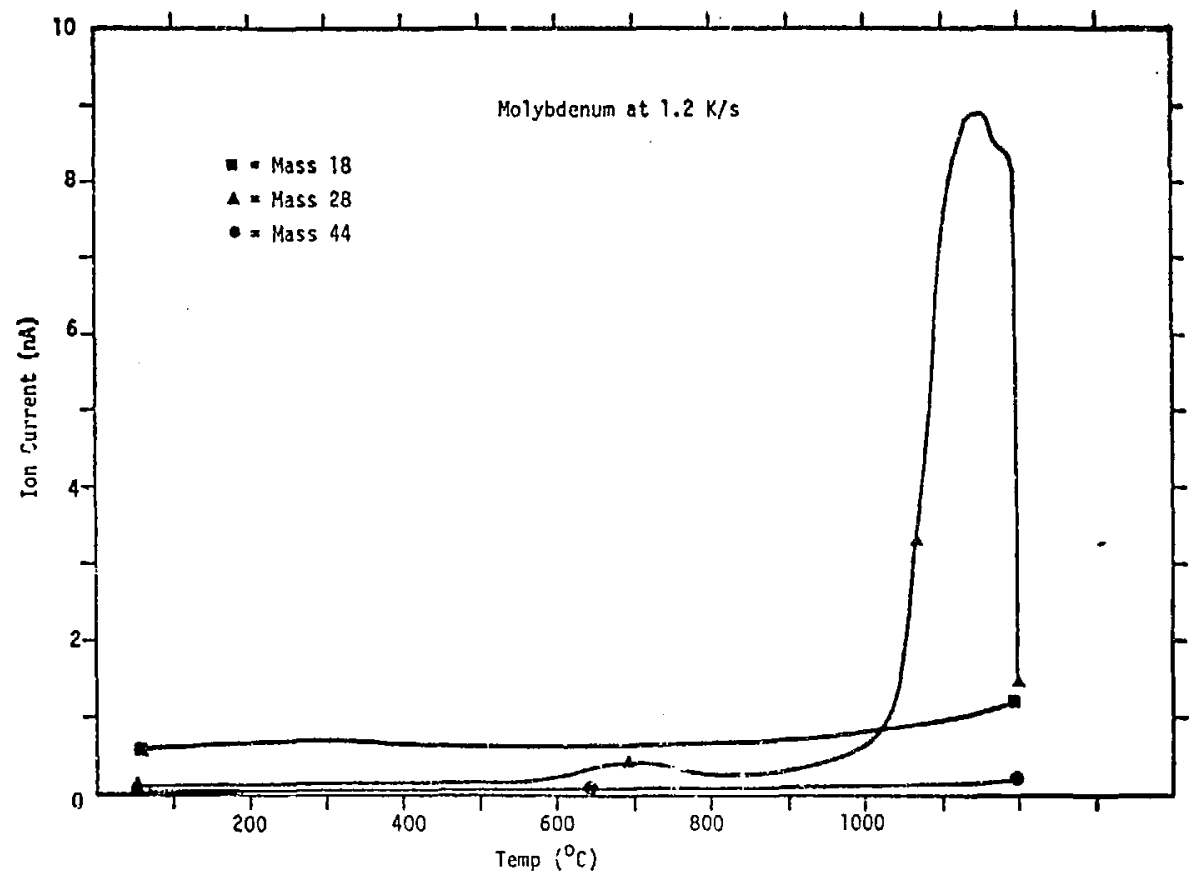

Fig. 9. Typiral outgassing specira from molybdenum foil heated at $\overline{1.2 \mathrm{~K} / \mathrm{s}}$. The constant level at low temperatures and the rise at the very highest temperatures are vacuum system artifacts. 


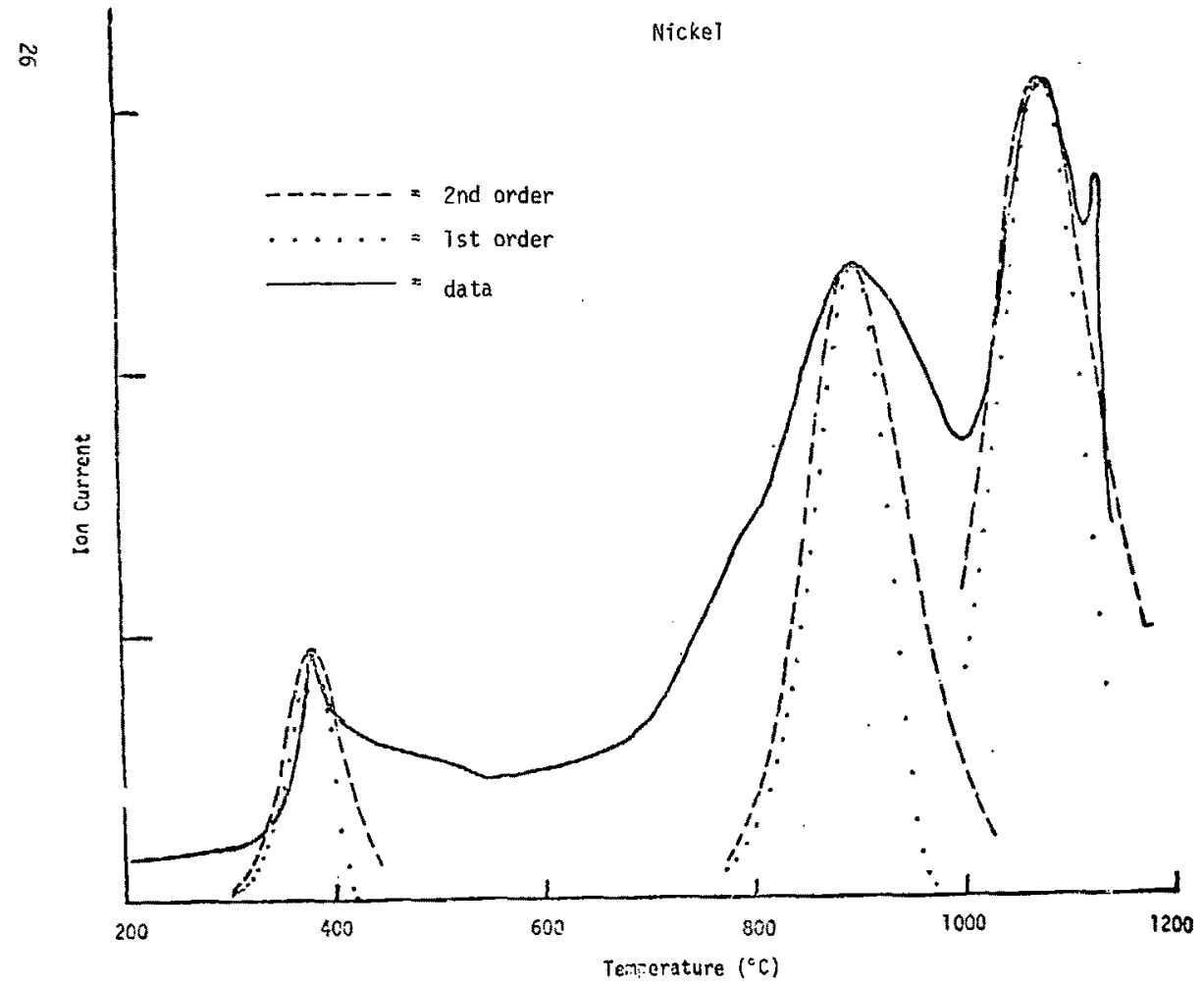

Fig. 10. Comparison of various theoretical desorption spectra with data from a silijle nickel desorption of carbon monoxide. 


\section{Copper}

Copper was the only metal studied which showed hydrogen to be a major desorbing species. All of the samples did not display the first-order peak(s) as seem in Figure 11. The peak when observed, occurs at $640^{\circ} \mathrm{C}, 57 \mathrm{kcal} / \mathrm{mol}$ first-order desorption and contains about $2 \times 10^{15}$ molecules of hydrogen $/ \mathrm{cm}^{2}$. At temperatures over $800^{\circ} \mathrm{C}$, the rising edge of a broad peak is observed but not portrayed on Figure 11. The entire peak was riot observed because the ramp was terminated at $900-950^{\circ} \mathrm{C}$ to forestall the sample sticking to the heater. This peak may be due to hydrogen diffusing from the bulk. Oxygen, carbon dioxide, and carbon monoxide are also noted to desorb. Fiqure 12 shows the oxygen desorption; at least 3 peaks are apparent. These appear to be first order. The first occurs at $365^{\circ} \mathrm{C}$, $33 \mathrm{kcal} / \mathrm{mol}$; the second at $520^{\circ} \mathrm{C}, 49 \mathrm{kcal} / \mathrm{mol}$; the third at $575^{\circ} \mathrm{C}, 53 \mathrm{kcal} / \mathrm{mol}$. The contain in total $10^{13}$ molecules $/ \mathrm{cm}^{2}$. The carbon dioxide and carbon monoxide desorption have the same general shape differing only in amplitude which reflects the thermodynamic equilibrium partition of the two species at the desorption temperature. The spectra are quite complex (Figure 13). The first peak occurs at $400^{\circ} \mathrm{C}, 42 \mathrm{kcal} / \mathrm{mol}$ if first order; the major peak occurs at $590^{\circ} \mathrm{C}, 54 \mathrm{kcal} / \mathrm{mol}$ and appears to be first order. The total gas desorbed was $1 \times 10^{14} / \mathrm{cm}^{2}$ and $7 \times 10^{13} / \mathrm{cm}^{2}$ for carbon dioxide and carbon monoxide, respectively.

\section{Copper 2\% Beryllium Alloy}

Copper $2 \%$ beryllium alloy (CuBe) behaves somewhat like copper. Hydrogen is desorbed only at the highest temperatures, with no peaks below $850^{\circ} \mathrm{C}$, i.e., $\approx 20^{\circ} \mathrm{C}$ below the melting temperature. Carbon monoxide is the major gas desorbed. figure 14 shows the carbon monoxide desorption spectra after various treatments of the cuBe. Carbon monoxide amounts to $6 \times 10^{14}$ molecules $/ \mathrm{cm}^{2}$ under the largest peak. The temperatures of the peaks and corresponding binding energies are $450^{\circ} \mathrm{C}, 45 \mathrm{kcal} / \mathrm{mol} ; 675^{\circ} \mathrm{C}, 59.4 \mathrm{kcal} / \mathrm{mol} ; 775^{\circ} \mathrm{C}, 66 \mathrm{kcal} / \mathrm{mol}$. Approximately 7 and $10 \%$, respectively, of oxygen and carbon dioxide are desorbed at the same temperatures as the carbon monoxide. 


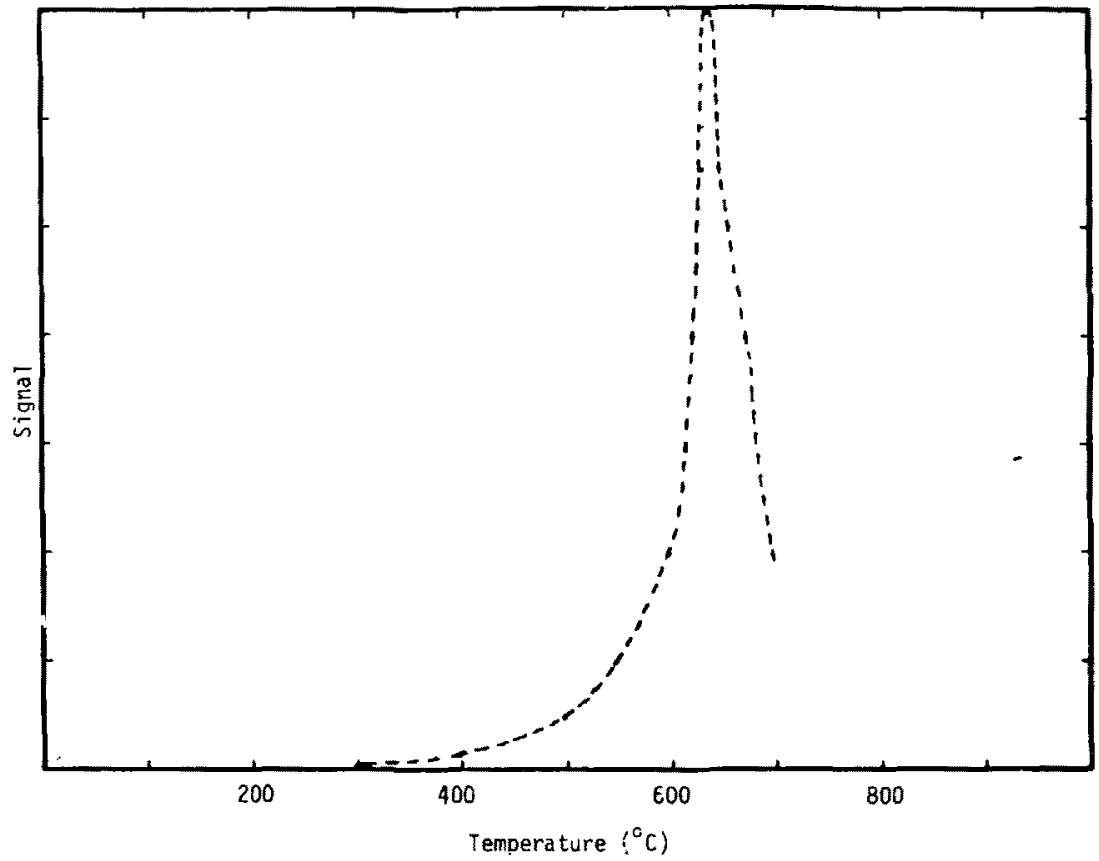

Fig. 11. Low temperatıre hydrogen desorption peak from copper. 


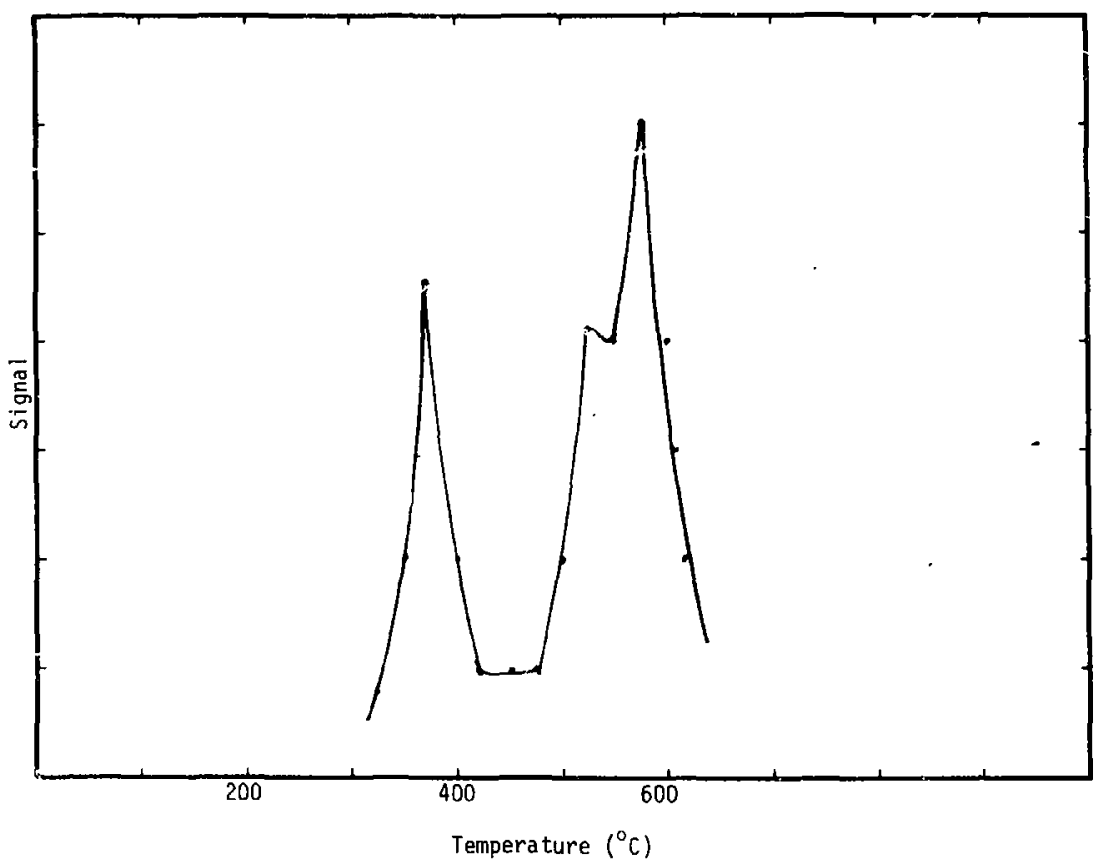

Fig. 12. Oxygen desorption spectra from copper. 
岩

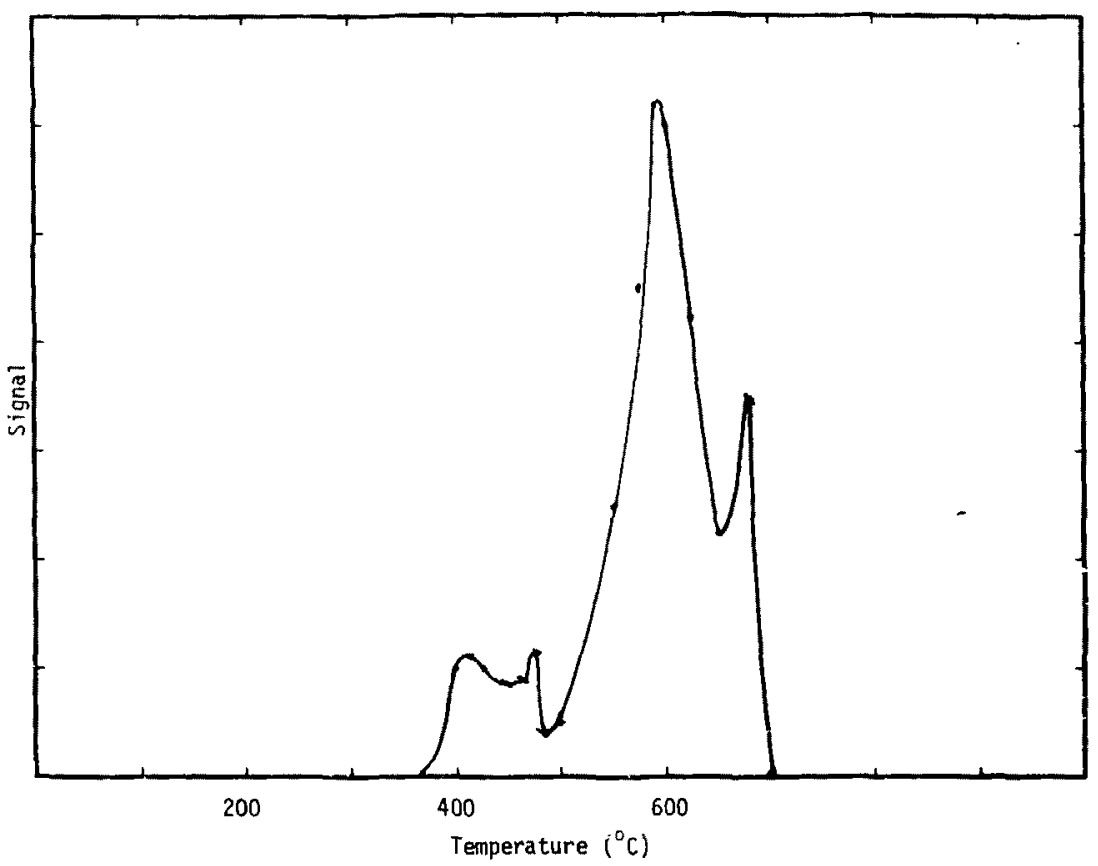

Fig. 13. Carbon dioxide desorption from copper. 


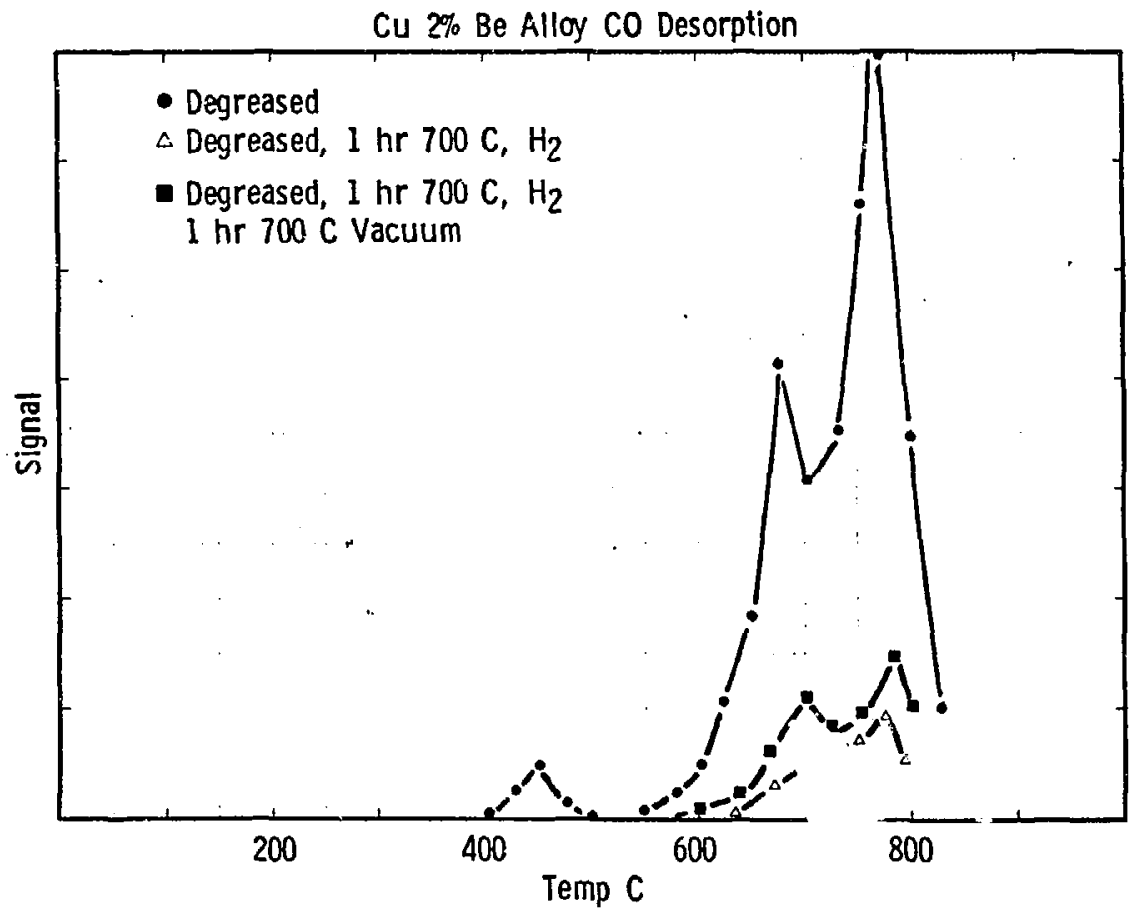

Figure 14 
Molybdenum Sealing Glass Ceramic (Mexin)

Hydrogen was the principal gas desorbed from the glass ceramic we measured. The material was in its fired (crystallized) form. Figure 15 shows the hydrogen $c$ sorption spectra. The upper curve was measured after the ceramic had been abraded with silica and cleaned. The lower curve is after cieaning only. The peaks are broad. They can be explained on the basis of hydrogen diffusion from the bulk (actually a layer $\approx .01 \mathrm{~cm}$ thick), with $\mathrm{D}_{0}=1 \times 10^{-3} \mathrm{~cm}^{2} / \mathrm{s}$ and $E_{d}=$ $11 \mathrm{kcal} / \mathrm{mo}$ ?. This compares $t$, Perkins' and Begeal's $\mathrm{s}^{22}$ reported values for deuterium diffusion in vitreous silica of $D_{0}=5.1 \times 10^{-4} \mathrm{~cm}^{2} / \mathrm{s}$ and $E_{d}=10.5 \mathrm{kcal} / \mathrm{mol}$. The agreement is probably fortalitous in light of the many simplifying assumptions made in the calculations based upon the measured desorption. The apparent gas quartities were $1.4 \times 10^{16} / \mathrm{cm}^{2}$ lower curve, $3.0 \times 10^{16} / \mathrm{cm}^{2}$ upper curve. The difference in the quantity of water desorbed depending upon whether or not it received abrasive treatment is even greater. Figure 16 shows the water desorption spectra from glass ceramic. The upper curve was from an abraded sample and contains $2 \times 10^{15}$ molecules $/ \mathrm{cm}^{2}$. It peaks at about $250^{\circ} \mathrm{C}$. The first-order binding energy is $32 \mathrm{kcal} / \mathrm{mol}$. The lower curve is a non-abraded but cleaned sample containing $1.1 \times 10^{14}$ molecules $/ \mathrm{cm}^{2}$. The $450^{\circ} \mathrm{C}$ peak has $48 \mathrm{kcal} / \mathrm{mol}^{2}$ binding energy. The only other appreciable gas observed was methane. It was not observed from all samples. A spectrum from an abraded sample is shown in Figure 17. The lower temperature peak contains about $2 \times 10^{13}$ molecules, the upper about $2 \times 10^{14}$ molecules. The peaks occur at about $185^{\circ} \mathrm{C}$ and $520^{\circ} \mathrm{C}$ with first-order binding energies of 28 and $49 \mathrm{kcal} / \mathrm{mol}$, respectively.

\section{Alumina Ceramic}

Alumina ceramic desorbs primarily hydrogen. It comes off as several firstorder peaks followed by a broad peak which may be diffusive (Figure 18). The first peak occurs at about $600^{\circ} \mathrm{C}$ and contains $27 \times 10^{15}$ molecules $/ \mathrm{cm}^{2}$ with a binding energy of $55 \mathrm{kcal} / \mathrm{mol}$. The total, including the apparent diffusive peak, hydrogen may be as much as $5 \times 10^{16} / \mathrm{cm}^{2}$. Typically, the total hydrogen desorbed is less than $1 \times 10^{16}$, with the first-order peaks accounting for $2-3 \times 10^{15} / \mathrm{cm}^{2}$. The only other gas emitted from alumina up to $1600^{\circ} \mathrm{C}$ is methane. Methane is emitted as a first-order peak at $2760^{\circ} \mathrm{C}$ (Figure 19), $65 \mathrm{kcal} / \mathrm{mol}$, and amounts to $10^{10}$ tc $10^{15}$ molecules $/ \mathrm{cm}^{2}$. 


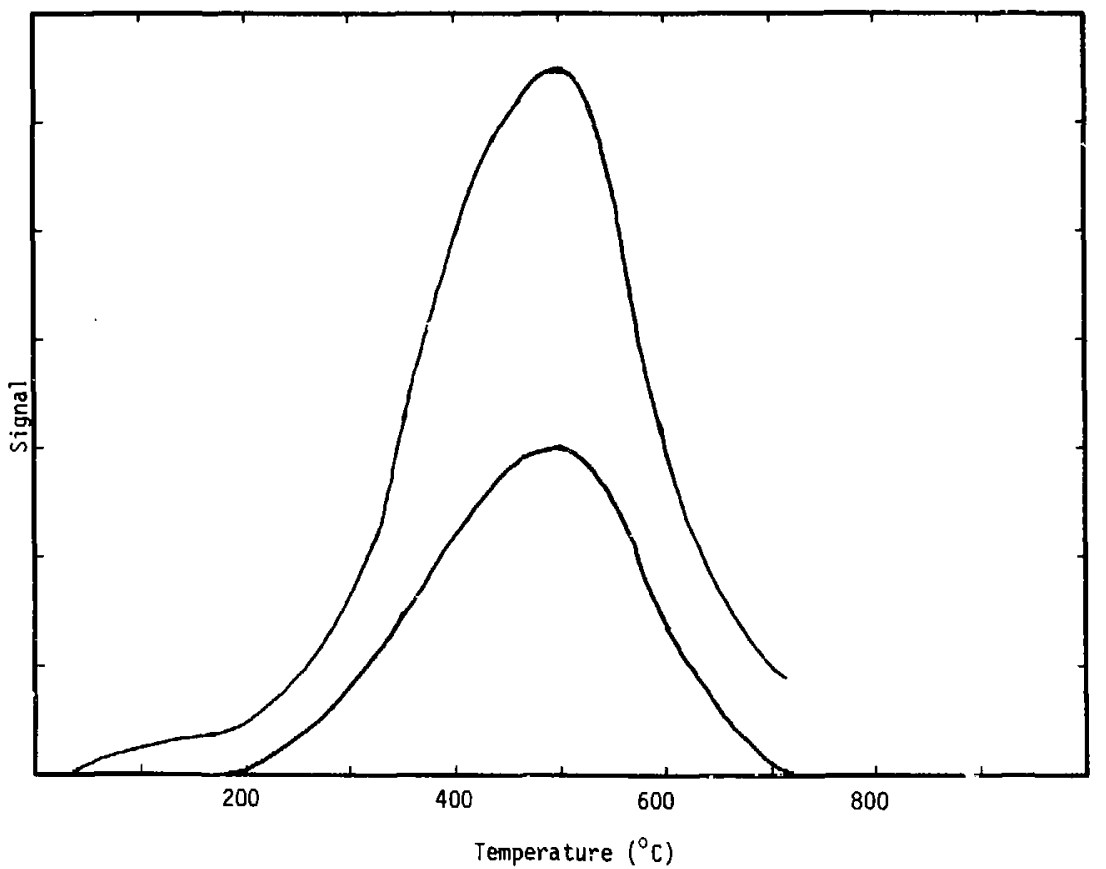

Fig. 15. Desorption of hydrogen from Mexim.

Upper curve silica abraded; lower curve un-

$\omega$

abraded; both had been cleaned. 
$\underset{\infty}{\omega}$

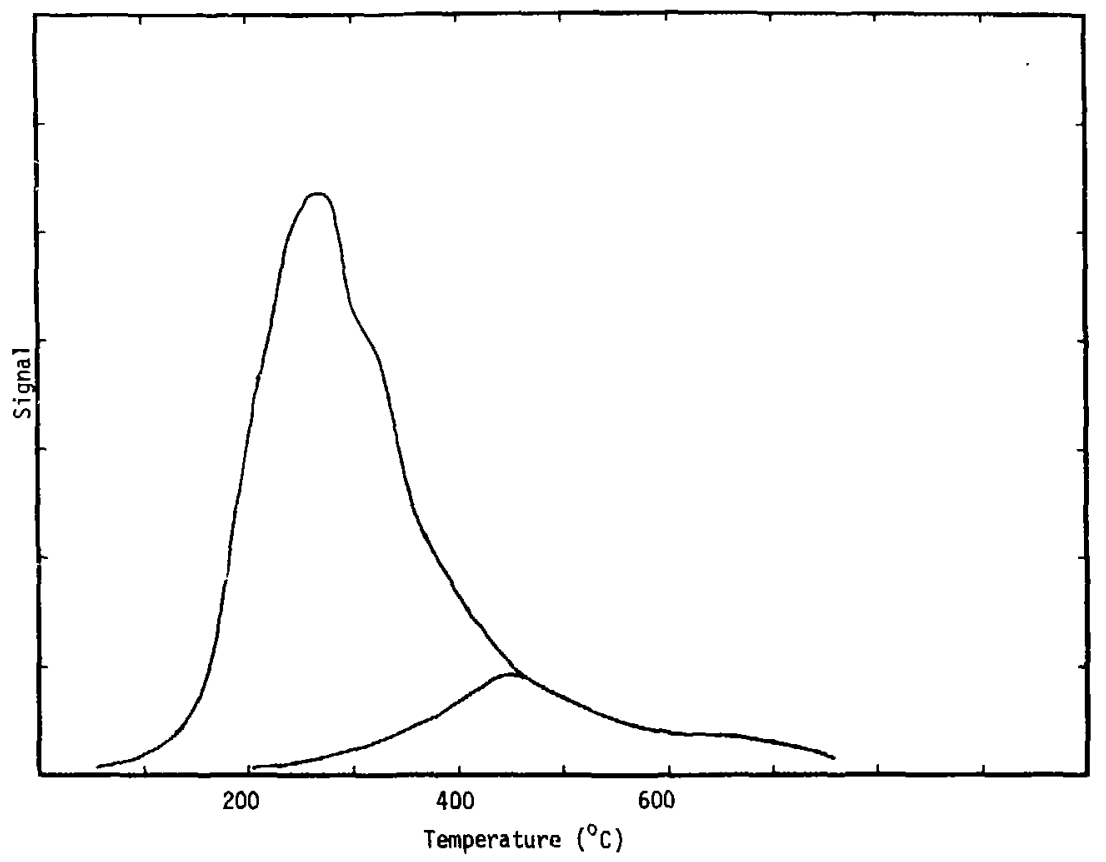

Fig. 16. Desorption of water from Mexim.

Upper curve silica abraded; lower curve unabraded; both had been cleansed. 


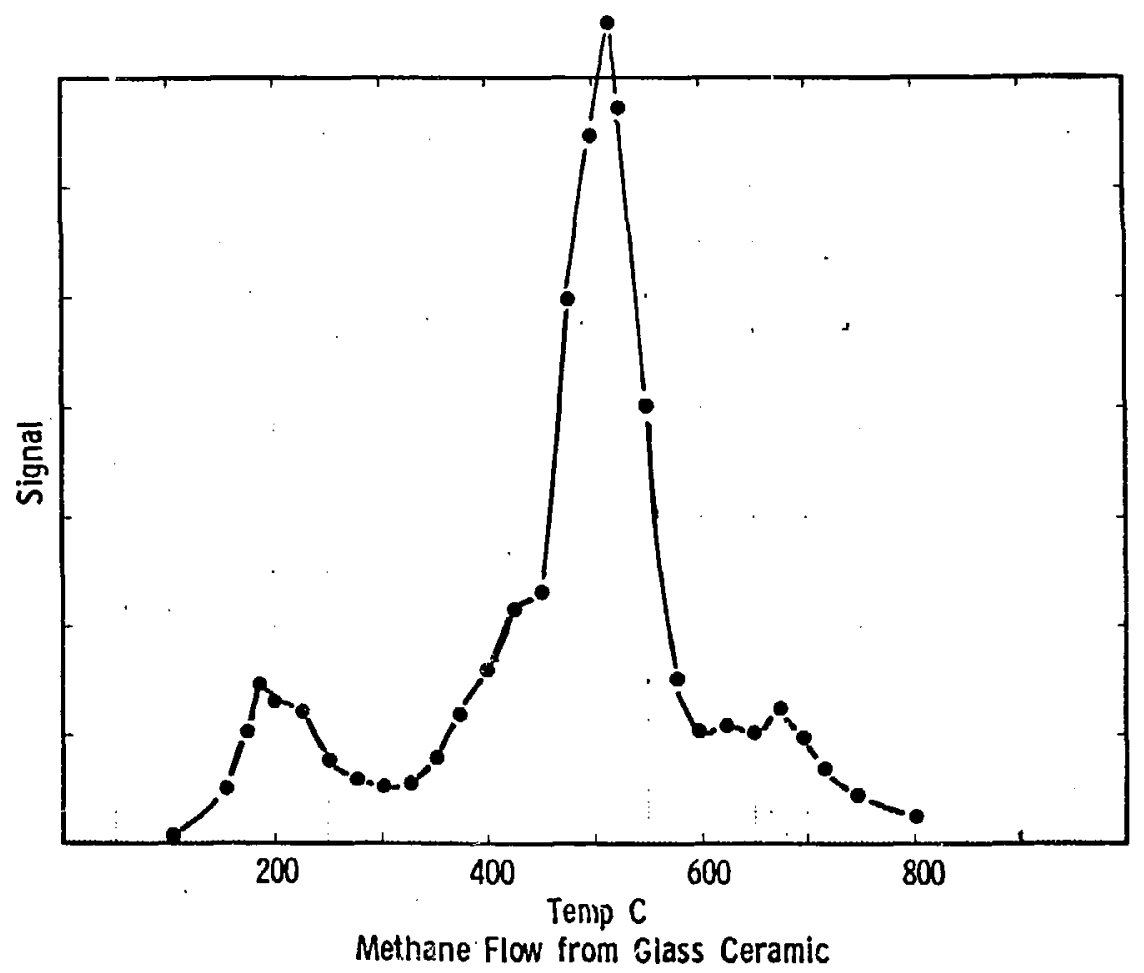

Figure 17 


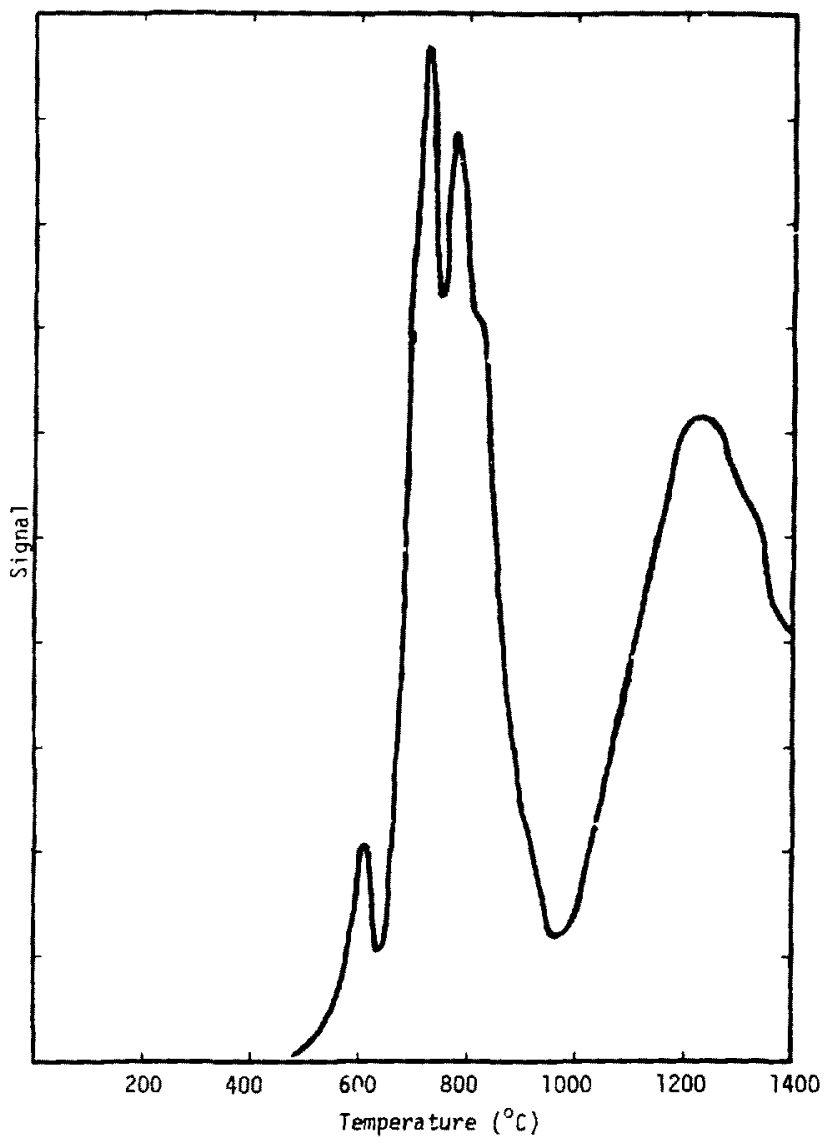

Fig. 15. Desorption of hydrogen from alumina ceramic.

36 


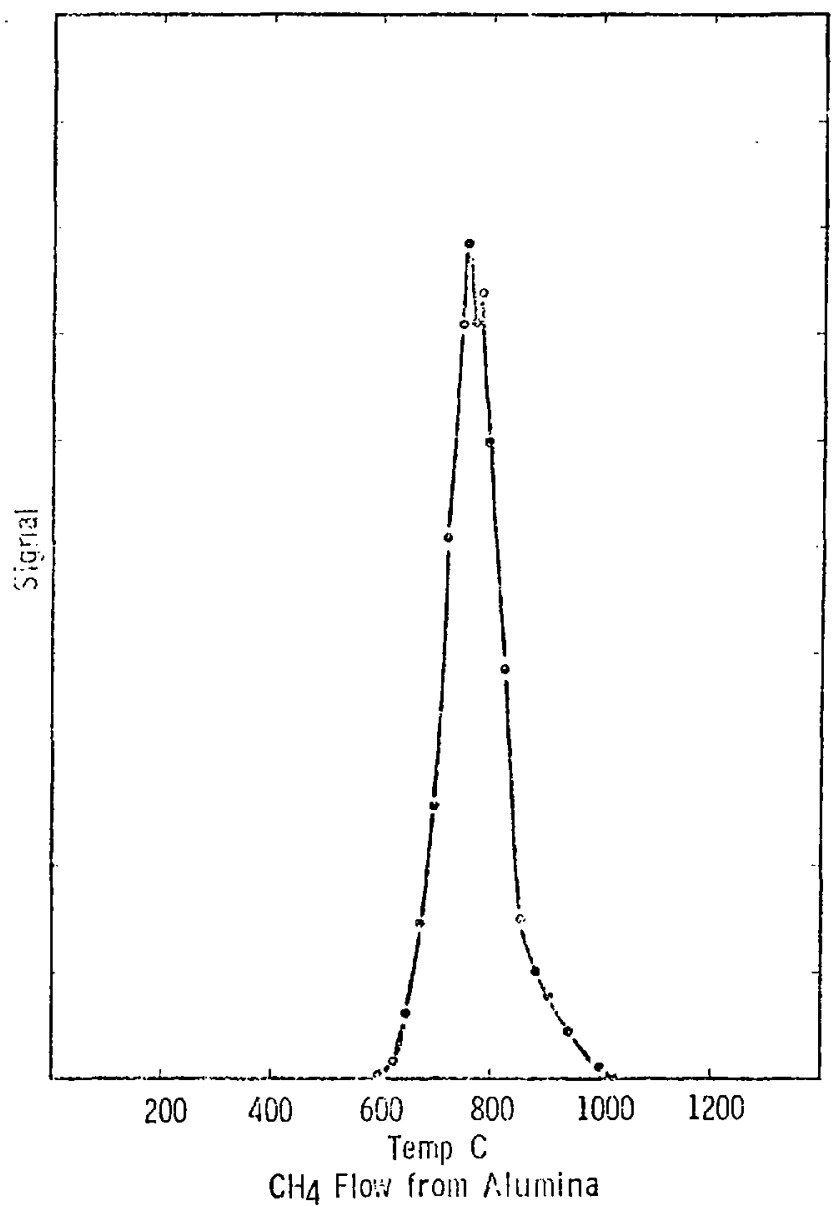

Figure 19 


\section{Predicted Outgassing Rates.}

The table gives rates of outgassing based upon the measurements reported in this paper for materials, stored at $300 \mathrm{~K}$ and $350 \mathrm{~K}$, before bakeout and after a $675 \mathrm{~K}, 10^{4} \mathrm{~s}$ bakeout.

\section{CONLUSIONS}

The value of a high-temperature bakeout becomes apparent when the several orders of magnitude reduction in moderate outgas rates occurs after suci: a bakeout. If the outgas rate is very small (a high desorption energy), then the bakeout has little impact, but the low flow should be no problem in either case. It can also be seen that desorption kinetics controlled by bulk diffusion have a much larger and long lasting impact on desorption. Raising the bakeout temperature will improve the long-term desorption characteristics. Therefore, it would seem prudent to subject materials which may desorb by diffucioi to a thoruugh high temperature vacuum firing before they are assembled into the final vacuum device but after they are to be exposed to high temperatures in the presence of gaseous atmospheres, e.g., $\mathrm{H}_{2}$.

\section{Acknowiedgements}

I wish to thank D. Begeal and R. Patrick for taking much of the data. W. G. Perkins and G. W. Mcclure for many interesting and heipful discussions on the data and its manipulatior, and L. Bustard for his critical reading and comments on the manuscript. 
TALE of PREDICTED outcas Rates (molecules/: $\mathrm{en}^{2}$ )

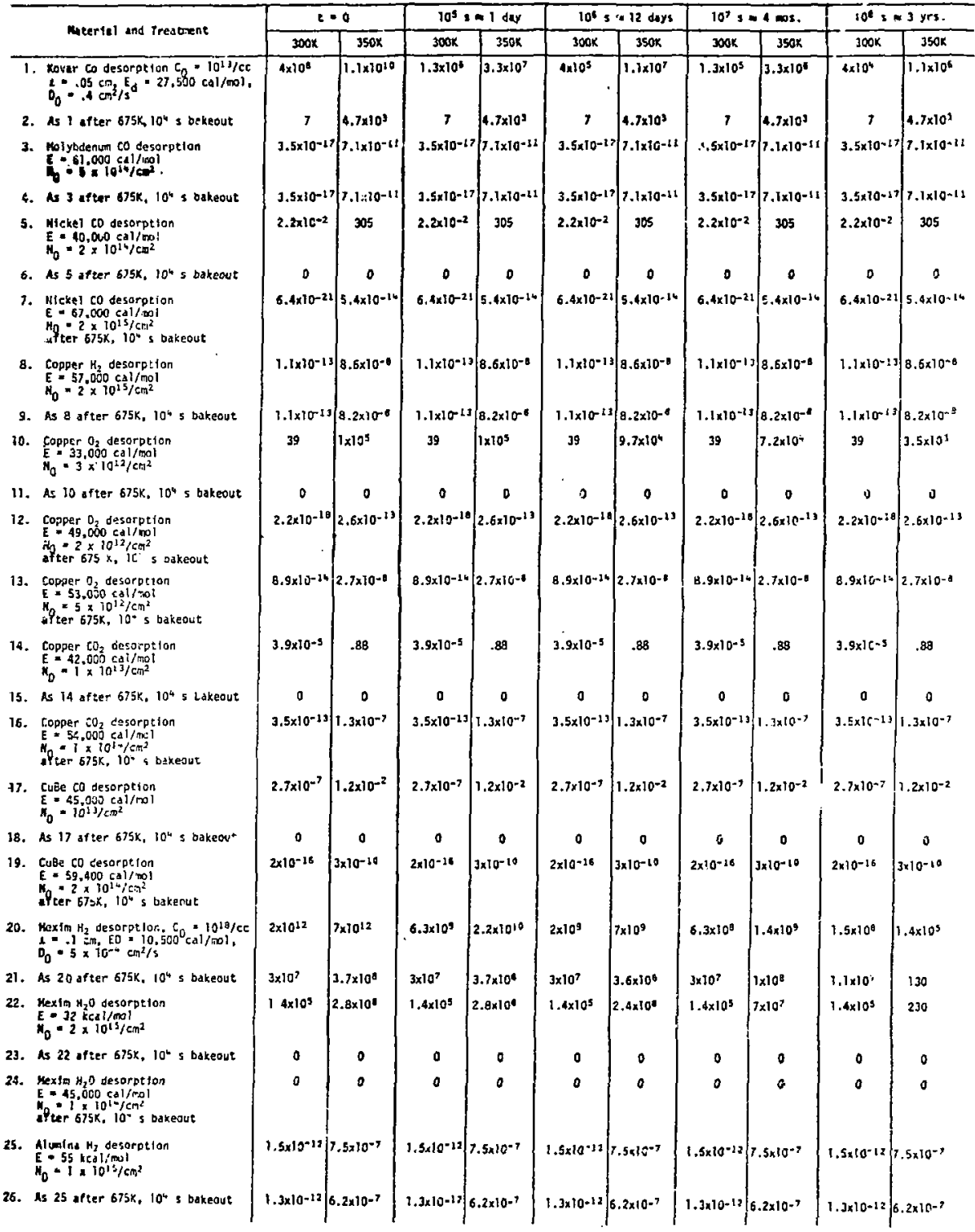




\section{REFERENCES}

1. Yale Strausser, Review of Outgassing Results, Varian Associate Publication WR-51, Palo Alto, Callf, undated.

2. J. P. Hobson, Proc, of the 1975 Isabelle Sumer-Study, Brookhaven Nationa] Laboratory, New York.

3. L. R. Apker, Industrial and Engineering Chemistry, 40, \#5, p.846-847 (1948).

4. A. W. Smith and S. Aranoff, Journal of Physical Chemistry, 62, p.684-686 (1958).

5. P. A. Redhead, Vacuum, 12, p.203-211 (1962).

6. Gert Ehrlich, Journal of Applied Physics, 32, p.4-15 (1961).

7. P. W. Tamn and L. D. Schmidt, Journal of Chemical Physics, 54, \#1, p.4775-4787 (1971).

8. G. Farre11, W. A. Grant, K. E. Rents, and G. Carter, Vacuum, 16, \#6, p. 295-298 (1966).

9. W. A. Grant and G. Carter, Physics and Chemistry of Glasses, 8, \#1, p. 35-37 (1967).

10. W. W. Brandt, International Journal of Heat and Mass Transfer, 13, p. 1559-1570 (1970).

11. D. A. King, Surface Science, 47, p.384-402 (1975).

12. 0. Edwards, Jr., Surface Science, 54, p.1-5 (1976).

13. G. Carter, B. J. Evans, and G. Farre11, Vacuum, 25, \$5, p.197-199 (1975).

14. S. E. Donneliy and D. G. Armour, Vacuum, 27, \#1, p.21-25 (1976).

15. K. L. Wilson and M. I. 8askes, "Deuterium Trapping in Irradiated 316 Stainless Steel," SAND77-8756, Apri? 1978.

16. R. C. Patrick, J. Vac. Science and Tech., 15, \#, p.133-134 (1978).

17. S. M. Ko and L. D. Schmidt, Surface Science, 42, p.508-524 (1974).

18. M. Abramowitz and I. A. Stegun, "Handbook of Mathematical Functions," p.223 and p.242-243, AMS-55, National Bureau of Standards, June 1964.

19. H. S. Carslaw and J. C. Jaeger, "Conduction of Heat in Solids, "p.97, 2nd Edition, Oxford-Clarendon Press, 1959.

20. J D. Fast, "Interaction of Metals and Gases, Kinetics and Mechanisms," p.126-127, Barnes and Nob7e, 1972.

21. M. R. Notis, $J$. of the American Ceramic Society, $45, \# 9,0.412-416$ (1962).

22. W. G. Perkins and D. R. Begeal, J. of Chem. Phys., 54, \#4, p.1683-1694 (1971) 